\title{
A FORMAÇÃO DE UM MERCADO DE MICROFINANÇAS NO SERTÃO DA BAHIA
}

\section{Reginaldo Sales Magalhães e Ricardo Abramovay}

\section{Introdução}

A trajetória histórica das mais importantes experiências de organização econômica voltadas para a inserção de populações rurais de baixa renda em mercados mostra uma surpreendente revelação: entre os casos bem-sucedidos, é flagrante a participação da maioria de seus dirigentes e associados no trabalho político e pastoral das Comunidades Eclesiais de Base. ${ }^{1}$

Algo inédito foi introduzido pelo trabalho pastoral na vida destas comunidades, a saber, a formação de um novo ethos que se expressa em formas singulares de organização econômica. A partir dos anos de 1970, nas catequeses, nas rezas, nos círculos bíblicos, nos cânticos e nas festas religiosas construíram-se os alicerces de comporta-

Artigo recebido em fevereiro/2006 Aprovado em janeiro/2007 mentos sociais e econômicos até então inexistentes. O trabalho religioso promoveu a emergência de um modo de ver e de se relacionar que possibilitou a formação de um tipo específico de racionalidade econômica. Isso não quer dizer que as decisões tomadas nas assembléias e nos conselhos de administração das organizações ou a forma de gestão financeira dos agricultores sejam, a todo o momento, guiadas por compromissos religiosos, mas sim que existe uma predisposição psicológica que ata cada indivíduo a um compromisso social na vida econômica. E esse compromisso, sim, encontra seus fundamentos no trabalho pastoral.

Qual o significado cultural desse processo histórico e quais suas conexões com a vida propriamente econômica? Há nessas experiências uma singularidade histórica de enorme importância: os comportamentos dos indivíduos com relação ao uso de seus recursos materiais e financeiros não se formam sobre a base da autonomia da esfera econômica na vida social. Ao contrário, é 
sobre a base da preservação dos valores básicos ligados à doutrina social da Igreja que se erguem organizações capazes de nortear a conduta dos indivíduos que delas participam. Solidariedade, união, organização social e luta não são princípios desprezados em relação a fatores mais propriamente econômicos, como eficiência, balanço contábil, sustentabilidade financeira ou sobras das cooperativas.

A compreensão dessas experiências revela que duas dimensões da vida social - há muito separadas pelas ciências sociais - são componentes intrinsecamente relacionados na formação das organizações econômicas e dos mercados: ética e economia. Parcela significativa dos estudos sociais contemporâneos procura reunificar aquilo que a história do pensamento econômico, desde seus primórdios, tratou como esferas distintas e até autônomas da vida social. Para Amartya Sen (1982), por exemplo, a abordagem "logística", "engenheira" da economia (que se ocupa dos aspectos relacionados à eficiência alocativa), e a abordagem "ética" (voltada ao tema aristotélico de "como devemos viver?") podem e devem integrar-se sob o ângulo científico. Albert Hirschmann (1986) segue, em seus trabalhos, essa mesma linha de raciocínio. E no campo da sociologia econômica contemporânea, os mercados, tributários das estruturas sociais e da regulação pública, não se encontram acima da ética, como bem mostra o trabalho tão importante de Neil Fligstein (2001).

Nas organizações econômicas que emergiram do trabalho popular das Comunidades Eclesiais de Base, a gestão racional desenvolveu-se em concomitância com a formação de um projeto político e social que orienta suas ações. São dois pesos de uma mesma balança, que ora pende para um lado, ora para outro, num equilíbrio sempre mediado por conflitos, mas são duas dimensões levadas em conta nas decisões dos indivíduos, nas regras das organizações e dos mercados e nas diferentes formas de controle social sobre os comportamentos.

Outra característica particular dessas organizações econômicas é que elas se assentam na formação de mercados que, apesar de seguirem padrões de gestão profissional dos negócios semelhantes aos das empresas modernas, têm embutido em suas instituições o compromisso com um projeto social. Sob esse aspecto, as organizações econômicas dos agricultores familiares, por exemplo, oferecem uma alternativa à oposição polar tão freqüente nas ciências sociais - e na política (Abramovay, 2004a). De um lado, a idéia de que os mercados são soluções mágicas para todos os problemas sociais; instâncias, de certa forma asociais, que não dependem de qualquer influência advinda de grupos, classes ou relações permanentes entre indivíduos e que funcionarão tanto melhor para a alocação de recursos quanto mais pairarem acima da sociedade. De outro lado, a idéia, justamente oposta, de que os mercados, como esfera autônoma da vida social, são incompatíveis com o bem-estar e com valores propriamente humanos e éticos. Este é o ponto de vista, por exemplo, de Jean-Paul Marechal em Humaniser l'économie (2000). Segundo ele, a economia de mercado não é capaz de conciliar desempenho econômico com progresso social. ${ }^{2}$

Ora, não são poucas as experiências oriundas dos movimentos sociais em que as visões de mundo formadas a partir da Teologia da Libertação possibilitaram a formação de mercados capazes de unificar a racionalidade econômica - expressa em contabilidade racional e na calculabilidade geral das atividades (Weber, 2000) - com a tentativa permanente de promoção de valores ligados à eqüidade e à participação direta dos indivíduos e grupos na gestão de seus negócios. Contra a polaridade entre o endeusamento e a diabolização do mercado opõe-se um terceiro ponto de vista, segundo o qual mercados são estruturas sociais e, mais do que isso, constituem campos (no sentido que Pierre Bourdieu atribui ao termo) e que, portanto, envolvem, de forma permanente, uma disputa entre diferentes grupos sociais em torno de sua dominação.

O que explica esta presença tão forte da ação e dos ideais éticos das Comunidades Eclesiais de Base na grande maioria das organizações econômicas voltadas para a valorização do trabalho de populações rurais de baixa renda? Que elementos intrínsecos do trabalho religioso levaram - de forma não intencional - a conseqüências imprevistas - e talvez até indesejadas - de vincular a luta pela justiça social a organizações pautadas pela racionalidade econômica? Como foi possível ligar a ação social movida por valores de natureza solidária e comunitária com aquela que se organiza de maneira impessoal em torno do cál- 
culo econômico, do balanço, da obtenção de ganhos e da necessidade de se "fechar as contas" da organização?

A formação de um mercado de microfinanças no sertão da Bahia é um exemplo - entre outros - desta espécie de quadratura do círculo. O importante - sob o ângulo sociológico - é compreender sua particularidade: trata-se de um mercado que resultou de um longo processo de mudanças culturais e institucionais, numa realidade onde o indivíduo e o ambiente típicos da tradição sertaneja são profundamente modificados na trajetória de formação de uma nova visão de mundo, de uma nova racionalidade econômica e de novas instituições. Na base dessas novas instituições está a formação de um padrão de comportamento racional, não só orientado por interesses individuais - buscados por meios coerentes e cada vez mais "calculativos" (Callon, 1998) -, como também portadores de uma ética cujos principais fundamentos são a cooperação e o compromisso com a redução da pobreza.

O clima semi-árido do território sisaleiro da Bahia provoca grande instabilidade na vida financeira das famílias, dos mercados e das organizações. Os mercados caracterizam-se por monopólios tradicionais, com regras que mantêm os agricultores em permanente endividamento e subordinação aos agentes econômicos que controlam as principais organizações locais e que gerem um amplo circuito financeiro informal, principalmente os COmerciantes de sisal e os ciganos. Em contrapartida, os próprios agricultores criaram também suas próprias estratégias de sobrevivência e estruturas autônomas de financiamento de suas necessidades de produção e consumo. Baseadas em relações históricas de cooperação, as instituições comunitárias tradicionais - com suas regras próprias de participação, troca e controle - contribuem para a viabilidade financeira das unidades familiares. Mas elas não são hábeis o suficiente para estabelecer relações externas à comunidade. Esse ambiente natural, social e cultural foi aos poucos sendo transformado, a partir da década de 1970, pelos padres missionários da Teologia da Libertação e pelos militantes comunistas que passaram a dirigir os sindicatos. A ação da Igreja, via Comunidades Eclesiais de Base, e os compromissos políticos, construídos em torno dos sindicatos e das associações, foram a base da superação de uma visão mágica que marcava as relações entre os sertanejo, a sociedade e a natureza, assim como de superação das relações tradicionais que asseguravam a permanência dos monopólios nos mercados locais. Essa nova racionalidade econômica, combinada com os compromissos éticos, formou o amálgama das redes de cooperação e das cooperativas de crédito que tornaram possível o acesso dos agricultores familiares a um novo mercado financeiro formal. Este é um caso em que a valorização da eficiência econômica se apóia em preceitos de natureza religiosa, mas que - contrariamente à situação clássica descrita por Max Weber - não envolvem, fundamentalmente, ascetismo e ética individualista. Vejamos a questão mais de perto.

\section{$O$ indivíduo e o ambiente típicos da tradição sertaneja}

O território do sisal compreende 27 municípios, das microrregiões do Nordeste, Piemonte da Diamantina e Paraguaçu do estado da Bahia. A produção e o beneficiamento de sisal são a principal fonte de renda da população, como também os elementos basilares da identidade sociocultural e das instituições sociais e econômicas regionais. O clima semi-árido, caracterizado por longos períodos de seca e média pluviométrica entre 300 e $550 \mathrm{~mm}$ ao ano, define o contexto natural no qual se estruturam as atividades produtivas e as relações sociais.

Os traços característicos e primordiais para a compreensão do universo cultural e econômico em que vivia a população rural pobre da região sisaleira há algumas décadas eram a subordinação aos monopólios tradicionais e a existência de um sistema padronizado de crenças (Nee, 2003, p. 4), valores religiosos e culturais, normas sociais e instituições, interiorizados na mente dos indivíduos (North, 1990) e que orientavam as transações financeiras comunitárias. Atividades lúdico-religiosas, como festas e rezas caseiras, criaram vínculos sociais e, junto com o trabalho, configuraram o âmbito e o funcionamento de uma unidade de relações sociais básicas.

Nas organizações econômicas comunitárias, típicas do sertão nordestino, os compromissos 
com Deus ou com o grupo de vizinhos nutriam e em muitos lugares isso ainda ocorre - as relações de reciprocidade e solidariedade nas trocas. A sobrevivência de cada membro das comunidades rurais da região sisaleira depende não da busca individual por resultados, mas, sobretudo, das tradições e dos valores da comunidade, que garantem coletivamente os meios de sobrevivência de todos. O sertanejo típico tem um senso de dever com a comunidade e uma vida regrada pelo temor a Deus; um modo de ver e agir tradicional sobre os mercados circunscritos às comunidades. É dessa forma que a realização de trocas financeiras que atendem aos interesses individuais se consolida a partir do fortalecimento de relações de cooperação e solidariedade, expressando, assim, o sentido social do próprio dinheiro (Zelizer, 1997).

As instituições comunitárias tradicionais são formas de organização da poupança comunitária. Mas, para que funcionem com baixos custos de transação, essas instituições orientam-se por diferentes regras, conforme as suas finalidades específicas. Os mutirões são atividades obrigatórias, pautadas por regras de reciprocidade e baseadas no compromisso com a comunidade. Já as caixinhas e consórcios são práticas orientadas pela participação voluntária e apóiam-se numa relação de confiança e compromisso com o grupo. Os bingos, balaios e campanhas são, por sua vez, instituições cuja participação também é obrigatória para todos os membros da comunidade que tenham recursos disponíveis para ajudar aos necessitados, guiados pela solidariedade e apoiados num compromisso religioso. A reciprocidade, muito mais do que o ganho individual, é o princípio organizador dessas formas de troca, mesmo em instituições onde objeto de troca é o dinheiro, como nas caixinhas.

Porém, fora das fronteiras comunitárias, a reciprocidade dá lugar à subordinação, e a solidariedade, à exploração. As relações econômicas são determinadas pela subordinação personificada (Abramovay, 2004b) aos monopólios tradicionais do mercado de sisal - comerciantes e agentes financeiros informais. O uso freqüente de mercados imperfeitos (Garcia-Parpet, 2003) que apresentam baixos custos de transação e, por isso, têm fácil acesso aos agricultores pobres criou, porém, monopólios assegurados ao longo da história por uma vigência legítima (Weber, 2000), baseada em convenções tradicionais e em coação. A existência de instituições tradicionais, como os monopólios e as instituições comunitárias, pressupõe certas disposições psicológicas e culturais nos indivíduos que sustentam esse padrão mental compartilhado, herdado de antigos costumes e crenças.

A "mão de gato", expressão pela qual é conhecido o comércio de sisal, exerce um grande poder de controle sobre a vida financeira dos agricultores: um controle personalizado e clientelista. A grande concentração de poder na mão dos comerciantes, as dificuldades de acesso a informações e a falta de possibilidades de escolha por parte dos produtores geraram um forte monopólio nos mercados agrícolas e, por associação, no mercado financeiro informal local, aquele que garante o financiamento da produção e da comercialização dos produtos agrícolas. É o mercado de "venda na palha", um mecanismo tradicional de controle que se dá via o endividamento (Abramovay, 1998 [1992]).

Outra importante instituição financeira tradicional da região sisaleira é o empréstimo de dinheiro a juros, agenciado pelos ciganos. Com tradições culturais e regras de comportamento próprias, eles vivem em grupos rigidamente fechados, coesos e governados por uma densa malha de preceitos morais. Medo, desconfiança e preconceito por parte dos não ciganos reforçam sua capacidade de controlar operações financeiras com segurança. As relações são personalizadas e as negociações, realizadas entre famílias, o que permite controlar de perto o risco dos empréstimos e o limite que pode ser emprestado a cada pessoa. A pressão constante e, em alguns casos extremos, a violência, garantem o pagamento.

O fiado - prática comum em todo o comércio das pequenas cidades da região - é um recurso financeiro necessário para todos os agricultores, especialmente nos períodos de seca. Da mesma forma que nas demais instituições, o conhecimento interpessoal possibilita a avaliação do risco de crédito e a pressão social necessária para o cumprimento do pagamento. Por outro lado, o endividamento constante torna cada grupo de consumidor dependente de um comerciante, o que lhe garante a formação de pequenos monopólios.

Com o objetivo primordial de tentar, a todo custo, estabilizar a renda, os agricultores usam esses mercados de altos custos financeiros, perpe- 
tuando uma condição de endividamento e de pendência. Vínculos personalizados, compromissos familiares, comunitários e senso de dever impõem o cumprimento efetivo das regras constituintes desses mercados. Em contrapartida, a gestão das unidades produtivas e domiciliares, por meio de estratégias complexas de consumo, poupança e crédito, é fei-ta num ambiente de profunda incerteza provocada pela condição climática característica do semi-árido. A vigência social restrita do cálculo econômico reduz a liquidez dos ativos, especialmente das poupanças monetárias, alte- rando os sentidos racionais, com os quais os sertanejos administram seus recursos, e fazendo com que a racionalidade do comportamento sertanejo não possa ser orientada exclusivamente por critérios econômicos. Os compromissos tradicionais, a reciprocidade nas comunidades e a dependência clientelista no mercado governam a vida social e econômica desse território.

Esse ambiente compõe um ethos social que não estimula a inovação, não facilita a busca de novas organizações econômicas e reproduz uma longa condição precária de acesso a mercados, a financiamentos, à produção e à própria sobrevivência. Como conseqüência, observa-se o endividamento permanente dos agricultores e a manutenção de sua condição de pobreza e de subordinação política e social.

A conquista da autonomia de uma parcela expressiva de agricultores familiares, da sua capacidade de buscar novos mercados, de criar organizações que reduzam seus custos e a melhor organização da sua vida financeira tornou-se possível, recentemente, graças à formação de divesas organizações, entre elas as que representam o apogeu do processo de racionalização, as cooperativas de crédito. Tais organizações - como é próprio da racionalidade econômica - são frutos de um longo processo de desencantamento. O interessante é que esse processo foi construído passo a passo pelas Comunidades Eclesiais de Base, pelos sindicatos de trabalhadores e pela Associa- ção dos Pequenos Agricultores da Bahia (Apaeb).

\section{As mudanças culturais}

Três processos sociais contribuíram para a transformação do universo cultural dos sertanejos e das suas formas de interação com os mercados: 1) a Igreja promoveu um processo de mudança no padrão tradicional de relações sociais com os mercados; 2) posteriormente, a organização das associações comunitárias e dos sindicatos possibilitou a continuidade de relações tradicionais e o acesso a novos mercados orientados por uma nova cultura política; e 3) o trabalho educativo da Apaeb, uma organização não governamental formada no âmbito das Comunidades Eclesiais de Base, ampliou a capacidade de cálculo e de planejamento tanto da vida produtiva como da vida doméstica dos sertanejos.

O sertanejo típico traz de sua tradição características culturais que apresentam fortes relações com seu comportamento econômico. Uma delas é sua visão da natureza. Perpetuam-se explicações mágicas, na tentativa de racionalizar e orientar o comportamento, inclusive o planejamento da produção e a organização financeira do domicílio, em face dos fenômenos físicos. Os dias de santo, com suas respectivas festas, rezas e rituais, têm a mesma importância que os preços para as decisões econômicas. Outra característica determinante para o com- portamento econômico - decorrente da pobreza e da dependência em que ele se encontra com relação aos que financiam sua própria subsistência - está no círculo das relações sociais do sertanejo tradicional, e, sobretudo, na resignação, na subordinação, na fidelidade ao compadrio, na expectativa paternalista com relação ao Estado e nos vínculos éticos, religiosos e afetivos que ligam os indivíduos a um mundo de obrigações sob estrito controle comunitário. Tais visões tradicionais sobre a natureza e a sociedade apresentam uma forte influência sobre o comportamento dos indivíduos diante de suas decisões econômicas e das regras estabelecidas no mercado.

Por que a religião apresenta essa estreita relação com a economia? Segundo Flavio Pierucci,

[...] não é possível explicar nem mesmo a economia e seus diversificados desenvolvimentos sem levar a sério os aspectos essenciais da história cultural, sobretudo da vida religiosa (2003, p. 179).

A chegada à região sisaleira de um grupo de padres e freiras italianas na década de 1970 é, paradoxalmente, o início de uma importante ruptura com o tradicionalismo. Os "círculos bíblicos", 
as celebrações coletivas e as festas religiosas foram as primeiras e mais elementares experiências de construção de uma nova forma de coesão social. As práticas religiosas organizadas por leigos e lideranças comunitárias tinham, além do caráter catequizador, a missão de promover discussões sobre a realidade local, os problemas dos agricultores, sobre a importância das organizações, do levantamento e da articulação das suas reivindicações (Oliveira, 2002).

A Teologia da Libertação era o fundamento político-religioso da ação das Comunidades Eclesiais de Base. A estratégia pedagógica de conscientização social por intermédio da fé consistia no uso de um método educativo, normalmente identificado pelo tripé "ver-julgar-agir", cujo significado compreendia a análise, seguida de uma discussão em pequenos grupos, com a população local sobre seus problemas mais graves. Nesse contexto, religiosos e leigos, especialmente orientados para essas funções, aprofundavam a compreensão do problema sob o ângulo da fé, relacionando as questões éticas e práticas ao evangelho e a explicações políticas e sociológicas. Daí resultava a elaboração, junto com as comunidades, de um plano de ação e luta (Novaes, 1987). Como testemunhou uma liderança local:

[...] nessa época era cego, assim não entedia de nada, de sindicato nem de associação e através deste trabalho com os padres italianos que teve aqui que a gente [...] começou a se organizar e fazer reunião nas comunidade, formamos uma diretoria e tomamos o sindicato da mão dos político. E aí pronto o povo se organizando cada vez mais, formamos a associação aqui na comunidade em 85. Foi a primeira associação. A gente lutava por melhoria de vida na comunidade. Pra reivindicar os direitos da gente na prefeitura, o prefeito em nome das pessoas da comunidade só fica mais difícil da gente conseguir então em nome da associação o povo tem mais força de conseguir. Nós pedimos aguada, várias coisas a gente conseguiu na época (Erenita Leonice de Oliveira, Valente, 2004).

Isso mostra que a Teologia da Libertação não estava preocupada apenas com a salvação das almas, mas principalmente com a vida das pessoas. O interesse religioso está muito mais voltado - e segundo Weber esta foi uma tendência nas religiões cristãs ocidentais - para o "mundo de baixo", para as soluções de problemas da vida concreta e menos para os problemas de ordem transcendental. Dessa forma, o trabalho religioso tornou transparente uma realidade social até então muito obscura, fazendo com que a visão de mundo tradicional fosse, aos poucos, sendo substituída por uma visão crítica e racional da realidade. Mudando a visão social segundo a qual "o mundo é assim porque sempre foi assim" para outra que vê um "mundo que pode e deve mudar". Mas o método das Comunidades Eclesiais de Base foi ainda além da mudança de visão dessa população: promoveu a confluência do aspecto filosófico maior embutido na tentativa de imprimir sentido aos textos religiosos com as necessidades práticas da luta dos trabalhadores. Dessa nova visão de mundo surgiram novas organizações.

O indivíduo formado nas reuniões das Comunidades Eclesiais de Base e nas lutas sindicais crê profundamente que sua sobrevivência depende dos laços familiares, comunitários e associativos que conseguir formar e conservar. A diferença resultante desse processo formativo do trabalho religioso foi estimular laços sociais que antes se davam em torno de antigas relações comunitárias, a partir da adesão consciente a um corpo de idéias, a uma cultura política (Abramovay, 1981, p. 135).

Em parceria com a paróquia da região, o Movimento de Organização Comunitária (MOC) passou a desenvolver um trabalho educativo e de apoio às organizações comunitárias e às oposições sindicais. ${ }^{3}$ Essas organizações basearam-se não só nas tradicionais relações comunitárias, mas também numa união de interesses racionalmente motivados, fruto do trabalho político-religioso. Uma combinação de tradição e modernidade passou a caracterizar, então, a vida comunitária deste território. A modernização da vida rural não provocou - ao contrário do que ocorrera em outros processos de incorporação de comunidades à esfera da economia moderna - a desestruturação das relações tradicionais, nem o enfraquecimento das relações de cooperação. Ao contrário, somou-se ao objetivo das antigas tradições comunitárias - que era integrar seus membros num tipo de economia semifechada - o papel das associações comunitárias de constituir elos de conexão entre as comunidades e 
as redes externas. A partir dessas relações de cooperação, que garantiam condições mínimas de sobrevivência, foram forjadas relações associativas que permitiram novas conexões com o mercado. Às regras informais das relações comunitárias foi incorporado um conjunto de formas modernas de organização, como a constituição jurídica de associações, a definição de estatutos e regimentos para o funcionamento dos grupos, o planejamento racional das ações, o uso da contabilidade na gestão dos recursos coletivos e a assinatura de contratos entre os indivíduos e as organizações. A mudança na vida religiosa abriu, assim, o caminho para a formação de uma nova relação com o mundo secular.

Uma das organizações mais importantes oriundas desse processo de mudança cultural foi a Apaeb, que teve um papel determinante na formação da racionalidade econômica dos agricultores. O trabalho de capacitação e assistência técnica e as primeiras organizações financeiras desenvolvidas pela Apaeb levaram a uma importante transformação na visão dos agricultores sobre o clima e sobre os recursos naturais do sertão, como também provocaram importantes mudanças no comportamento econômico dos sertanejos.

A principal contribuição da Apaeb foi a introdução de uma prática de planejamento e de inovações tecnológicas entre os agricultores, o que vem ampliando suas habilidades na gestão dos recursos naturais e financeiros. Em 1995, foi lançado o "Programa de Convivência com a Seca", cujas diretrizes básicas eram o reordenamento da unidade produtiva familiar, o aproveitamento racional das áreas agrícolas, a preservação do meio ambiente, o gerenciamento das atividades tendo como parâmetro o mercado, a captação e o armazenamento de água, inovações tecnológicas para o armazenamento de alimentos (silos, feno, bancos de proteínas), o rebaixamento da caatinga, o aproveitamento da energia solar, o crédito e a assistência técnica (Oliveira, 2002).

Em 2000, o "Projeto Prosperar" aperfeiçoou a metodologia, incorporando métodos ainda mais racionais de diagnóstico, avaliação e planejamento das unidades de produção. Em dois anos, 1.530 famílias foram atendidas pela assistência técnica - diagnóstico das condições sociais, da ocupação da mão-de-obra familiar, da renda, do consumo familiar, do acesso ao crédito, das con- dições de habitação, de saneamento, de bens domésticos e da divisão social do trabalho familiar entre os sexos. Com este diagnóstico em mãos, técnicos e agricultores, em oficinas e visitas de campo, fazem o planejamento produtivo e de melhoria das condições de vida. Com base nisso, são definidas as atividades a serem financiadas e implementadas por cada família. Em parceria com a Apaeb, realiza-se um trabalho de assistência técnica e difusão de tecnologias por meio de "agentes de convivência com o semiárido", agricultores indicados por sindicatos de trabalhadores rurais, Igreja ou outras instituições locais, que são capacitados e acompanhados por técnicos da organização.

Essas três instituições, que ajudaram a desenvolver, ao longo de quase trinta anos, o senso de dever, os compromissos políticos e as ferramentas de cálculo, passaram a guiar o comportamento dos indivíduos e constituir novos condicionantes da racionalidade econômica. O auge desse processo de racionalização das organizações econômicas dos sertanejos se deu com a constituição das cooperativas de crédito e a formação de um mercado financeiro com características específicas para o território do sisal.

\section{As estruturas sociais do novo mercado financeiro}

Quatro experiências de organização financeira foram fundamentais para a aprendizagem organizacional, que resultou nas cooperativas de crédito. A Poupança Apaeb, o Fundo de Investimentos, o Fundo Rotativo e o Fundo Solidário, embora tendo tido curta duração, pequena abrangência, resultados limitados e, em alguns casos, até mesmo questionáveis, introduziram na vida financeira dos sertanejos da região sisaleira serviços financeiros mais acessíveis, mais baratos e mais adequados às demandas locais, bem como mecanismos formais de controle. A avaliação dos erros e acertos na gestão desses serviços financeiros levou à criação das cooperativas de crédito. Em suma, os próprios protagonistas dessas organizações perceberam que seu formato institucional conduzia à inadimplência, à quebra dos compromissos, fazendo com que o desrespeito às regras elementares dos contratos 
de empréstimo ameaçasse a coesão buscada pelo trabalho comunitário. A criação de organizações formais com regras estritas, então, tornou-se um meio prático de fazer da racionalidade econômica um meio de fortalecimento da própria luta por solidariedade social. É interessante observar a ambigüidade da própria Igreja nesse sentido, ainda mais porque a experiência dos fundos rotativos se multiplicou por outras regiões do país: de um lado, estimula o acesso ao crédito; de outro, imprime-lhe uma forma organizacional de natureza comunitária em que não existem mecanismos coercitivos que garantam o pagamento das dívidas contraídas. O resultado é, evidentemente, a inadimplência generalizada e a desmoralização da própria organização coletiva. As cooperativas de crédito originárias de iniciativas de movimentos sociais no Brasil - tanto as do sertão da Bahia como as do Sistema Cresol de Crédito Solidário, no Sul do Brasil (Bittencourt e Abramovay, 2001; Junqueira e Abramovay, 2005) - são respostas a essas insuficiências das formas de compromisso comunitário diante das exigências próprias à formação de um mercado de crédito.

De fato, mais que uma organização, o que se criou foi um novo mercado que passa por uma complexa rede de organizações, fluxos de informações e intensa movimentação financeira por meio de variados serviços de crédito e de poupança. Até 2004 eram nove cooperativas de crédito, integrantes de uma associação chamada Ascoob (atualmente uma federação de nome Fenasccob) com 14 mil associados e um desempenho econômico, na média, comparável aos bancos e um resultado social bastante superior. Em dois municípios, Araci e Valente, segundo dados do Banco Central (2001), o volume das operações de empréstimos das cooperativas supera as operações dos bancos locais.

Como lideranças sociais de uma base social de baixa renda conseguiram formar uma organização financeira desse tipo? A resposta pode ser encontrada na organização social que garante as condições para a sustentabilidade desse mercado. As categorias analíticas oferecidas no trabalho decisivo de Neil Fligstein (2001) ajudam a compreender o fenômeno. Ele mostra que, contrariamente à visão convencional, os mercados não funcionam sobre a base de um leilão permanente em que os atores estão sempre dispostos a comprar pelo menor preço e a vender a quem oferecer a melhor cotação. Esta visão não leva em conta que a mais importante preocupação dos protagonistas de um mercado é estabilizar suas relações uns com os outros de forma a reduzir os impactos destrutivos que a imprevisibilidade do funcionamento dos mecanismos de preços lhes traz. Isso não se faz necessariamente - como bem mostra o trabalho pioneiro de Granovetter (1985) - por meio de contratos formais. Mas Fligstein avança teoricamente em relação à contribuição de Granovetter porque não caracteriza de forma genérica os mercados como redes, mas os concebe a partir de uma teoria da ação, na qual os indivíduos estão procurando, permanentemente, obter cooperação alheia e estabilizar os vínculos sociais que lhes permitem dominar ou, ao menos, sobreviver num determinado campo (Fligstein, 2001).

Ora, neste campo específico que são os mercados, a cooperação se estabiliza com base na resolução de quatro questões centrais: a) os direitos de propriedade, que determinam a quem pertencem os resultados econômicos das atividades levadas adiante nos mercados; b) as estruturas de governança, que estabelecem as modalidades de operação e os acordos aceitos como legítimos numa determinada situação; c) as regras de troca, que definem, por exemplo, a moeda e as taxas de câmbio a serem utilizadas num determinado mercado; e d) as concepçôes de controle, que exprimem expectativas e práticas consagradas por parte não só dos gestores, mas também dos acionistas das empresas. Nenhum mercado se estabiliza sem contemplar esses fatores fundamentais.

No caso das cooperativas de crédito, os direitos de propriedade são claramente definidos e diferem daqueles que caracterizavam os mercados dos quais dependiam tradicionalmente os agricultores, que agora possuem cotas que lhes dão direito a determinados montantes de empréstimos. A estrutura de governança desses novos mercados passa pela submissão das cooperativas às regras formais de controle do Banco Central, tornandoas concorrentes dos bancos comerciais neste segmento - muito pequeno, é verdade, mas, localmente expressivo - do mercado de crédito. Além disso, é uma governança que exige transparência em relação ao Banco Central e aos associados -valor decisivo na própria história cultural dessas 
organizações. As regras de troca vigentes são claramente estabelecidas e vinculam ao compromisso tradicional com a honra a obrigação assumida com os instrumentos de coerção para a recuperação dos recursos emprestados. O fato de tais instrumentos (protesto de título, por exemplo) não serem quase nunca empregados mostra a força dos vínculos comunitários na base do funcionamento das cooperativas. A concepção de controle sobre a cooperativa envolve a fusão entre a sustentabilidade financeira das operações e a necessidade de se atender a um público excluído do sistema financeiro formal. Contrariamente, por exemplo, ao Sistema Cresol de Crédito Solidário, do Sul do Brasil - composto exclusivamente por agricultores familiares -, as cooperativas de crédito da Ascoob estimulam a associação de comerciantes e mesmo de agricultores não familiares, numa lógica batizada como "Robin Hood": sem a presença de agricultores maiores e comerciantes, jamais as cooperativas poderiam ganhar a sustentabilidade financeira necessária para ampliar seus serviços financeiros aos mais pobres.

A gestão das cooperativas de crédito depende, pois, da manutenção de relações estáveis - e, nesse sentido, foi aberto um mercado inexistente até então - entre seus cooperados e de informações confiáveis para, de um lado, avaliar os riscos de crédito e, de outro, transmitir credibilidade, ou seja, criar uma base de confiança para que os cooperados depositem suas poupanças.

A viabilidade da poupança entre as populações de baixa renda tem sido alvo de diversas pesquisas recentes (Abramovay et al., 2004). A existência de recursos monetários nas mãos dos agricultores da região sisaleira é claramente percebida na observação do grande fluxo financeiro do mercado informal ou no surpreendente volume de depósitos nas cooperativas. Em muitas delas, os depósitos aproximam-se ou até superam os depósitos bancários. Com efeito, redução da assimetria de informação e dos custos de transação, mediante a formação de relações de proximidade, é resultado da formação de uma densa rede de organizações e de relações sociais (Magalhães, 2003).

A organização social cumpre ainda uma outra função, além de garantir as transações financeiras entre as cooperativas e os agricultores. A existência de um projeto político, que, nesse caso, se refere explicitamente a dois grandes objetivos convivência com o semi-árido e redução da pobreza -, anuncia, para usar a expressão de Karl Polanyi, uma racionalidade substantiva na gestão desse mercado. Contudo, seria fundamental haver um mecanismo de controle social autônomo e que não fizesse parte diretamente do sistema econômico. A existência de constantes conflitos de interesse entre diferentes grupos sociais - associados versus diretorias, diretorias versus gerentes, agricultores mais pobres versus comerciantes mostra que os resultados auto-regulados que poderiam ser alcançados no funcionamento desse mercado não correspondem aos interesses particulares de cada grupo social. Em outras palavras, a auto-regulação gerada exclusivamente pelo mecanismo de preços - neste caso, as taxas de juros - não seria suficiente para promover uma melhor alocação do crédito e da poupança entre os cooperados. Somente a existência de um espaço político de mediação de conflitos de interesses é capaz de integrar numa mesma organização diferentes interesses econômicos.

Tal mecanismo político convive com formas de gestão centradas na observação da eficiência econômica, da legalidade e do controle rigoroso da inadimplência. As cooperativas de crédito estão integradas num sistema (neste caso, o Sistema Sicoob) que possui regras para estimular sua segurança e sua rentabilidade financeira. São subordinadas também à regulamentação e à fiscalização do Banco Central. Mantêm, ainda, estruturas administrativas com o uso de contabilidade padronizada e transparente, auditorias regulares, sistemas de controladoria, métodos formais de controle de risco, contratos formais para controle de transações, prudência nas aplicações financeiras, parecer de conselhos fiscais e prestação de contas em assembléia. O interessante é que a adesão a esse tipo de racionalidade não levou ao abandono dos valores em torno dos quais a comunidade construiu historicamente a sua coesão. Os processos sociais descritos nesse trabalho mostram que a eficiência econômica e social das cooperativas de crédito da região sisaleira se explica, justamente, pelo vínculo forte entre a racionalidade econômica e a cultura política das organizações sociais da região.

Diferentes mercados integram-se numa mesma rede de relações econômicas e sociais (Granovetter, 
2002). A produção de sisal, a fábrica de tapetes, a produção de caprinos, as fábricas de laticínios e couros e os artesãos que manufaturam seus produtos integram-se, todos, numa rede com dois pontos principais de articulação: o trabalho político e educativo conduzido pelo MOC, pela Apaeb e por sindicatos dos trabalhadores rurais, de um lado, e os serviços financeiros coordenados pelas cooperativas de crédito, de outro. Uma rede interssetorial, mas com forte identidade territorial, é um campo fértil para o enraizamento das cooperativas de crédito nos sistemas de produção local. O conhecimento das condições comerciais, climáticas, tecnológicas e gerenciais dos empreendimentos e dos agricultores familiares permite às cooperativas oferecer serviços financeiros mais adequados às suas demandas específicas. A proximidade abre caminho para uma troca informal de informações imprescindível para a redução da assimetria de informações e dos riscos de crédito.

Essa rede de relações sociais, mediadas pelas transações financeiras, permite uma troca constante de informações que contribui para reduzir incertezas e fortalecer laços de confiança. Além das próprias cooperativas de crédito, sindicatos, associações, comerciantes, representantes de comunidades, organizações de mulheres etc. interagem com grande proximidade e freqüência, trocando informações sobre os riscos morais e as condições financeiras de cada ator. Forma-se, assim, um mecanismo social de redução dos riscos (Ferrary, 1999), que contribui para reduzir as assimetrias de informação e os custos de transação. Seus resultados são taxas de juros mais baixas e acesso mais amplo da população aos serviços financeiros.

\section{Conclusão}

Um longo processo de mudanças culturais criou as condições para a emergência de novas estruturas sociais e as bases institucionais para a formação de um mercado de microfinanças na região sisaleira. As crenças religiosas, as tradições e o modo específico de o sertanejo se relacionar com a natureza adquiriram novo significado pela ação política e religiosa. Houve um processo de diferenciação dos diversos significados da ação
(Cohn, 2003), que no "mundo encantado", perfaziam um amálgama de valores, confundindo os meios e os fins que orientavam as ações. Com o processo de racionalização, os fins econômicos tornaram-se mais nítidos, separados, regulamentados e formalizados, possibilitando o cálculo e a avaliação dos resultados da produção sem, contudo, desestruturar os valores e as tradições de solidariedade e cooperação.

A ação das comunidades eclesiais de base promoveu uma mudança cultural com forte impacto na organização econômica da população da região sisaleira. Com a racionalização, os agricultores familiares passaram a experimentar o aumento do uso de regras formais para a regulamentação das transações financeiras. A racionalidade econômica dos produtores adquiriu, então, um novo padrão, pois, com o acesso ao crédito, sua produção passou a ser mais diretamente influenciada pelos preços. A monetarização da vida financeira dos sertanejos levou a uma maior racionalidade na gestão dos recursos, ao promover o aumento do uso do dinheiro, principalmente para a poupança. Simultaneamente, o pagamento dos empréstimos passou a ser um parâmetro para a gestão da produção. Os agricultores começaram, mediante um trabalho de capacitação e assistência técnica no planejamento das unidades de produção, a desenvolver uma nova capacidade de gestão dos recursos. Dessa forma, as decisões das famílias em relação à gestão financeira - quanto e como poupar, quando vender ou quanto e onde tomar empréstimos - tornaram-se mais orientadas por parâmetros de mercado.

A criação das cooperativas de crédito provocou um rompimento do mercado financeiro local com o ambiente institucional tradicional, baseado em vínculos personalizados e clientelistas. Porém, isso não significou uma autonomização da vida econômica com relação aos laços sociais e seus substratos culturais. Novos vínculos, de novos tipos, sobrepuseram-se aos antigos. Não se formou um mercado auto-regulável, mas sim um mercado orientado por determinados princípios éticos, como a inclusão social e a sustentabilidade ambiental.

A compreensão sociológica sobre a formação do mercado de microfinanças da região do sisal tem importância crucial para o debate sobre 
a vida econômica de populações de baixa renda, com implicações tanto para a formulação de políticas como para o próprio debate teórico sobre os mercados. Este estudo mostra que as políticas de promoção do desenvolvimento de regiões e de populações pobres devem levar em conta os recursos de que as próprias populações dispõem e as condições institucionais que os grupos sociais precisam desenvolver para ter acesso aos mercados. Ou seja, tal acesso não pode ser pensado apenas como o resultado de políticas públicas e da formação de novas organizações, mas, sobretudo, como o resultado de processos de desenvolvimento cultural e institucional.

Quanto ao debate teórico, discutimos, em primeiro lugar, os limites dos pressupostos individualistas da economia neoclássica e a importância de análises históricas e empíricas para se compreender o comportamento real dos mercados. As instituições são condicionantes básicos do comportamento individual e do funcionamento do mercado. A racionalidade econômica é fruto da conjunção de ambientes institucionais com características individuais, e os interesses são definidos socialmente, pelas instituições. A compreensão da especificidade e do sentido de cada configuração de interesse e relações sociais depende do estudo sociológico, antropológico e histórico dos padrões culturais, de suas transformações e da forma como determinam o cálculo nos comportamentos econômicos. Os mercados estão subordinados a estruturas sociais que, por esse motivo, adquirem características específicas em cada território, resultado das condições institucionais, naturais e culturais.

\section{Notas}

1 Para citar apenas alguns exemplos: Sistema Cresol de Cooperativas de Crédito na região Sul do Brasil (Junqueira e Magalhães, 2007); Centro de Tecnologias Alternativas da Zona da Mata de Minas Gerais (Cardoso et al., 2004); Organização da Agricultura Familiar no Vale do Jequitinhonha (Ribeiro et al., 2000); Organização Econômica em Gurupá, na região amazônica (Pace, 1992); Organização dos Seringueiros no Acre (Costa Sobrinho, 1992); Formação de Empreendimentos de Pequeno Porte, também na Amazônia (Becker e Léna, 2002); Desenvolvimento da Agroecologia no Rio Grande do Sul
(Alves, 2004); e Organização dos Agricultores Familiares na Paraîba (Novaes, 1997).

2 Perret e Roustang (1993) compartilham também essa visão. Nessa mesma linha, o livro de Ferrester (1996) talvez seja a expressão mais emblemática.

3 Fundado em 1967, com sede no município de Feira de Santana, o MOC é uma das mais ativas organizações brasileiras voltadas para a luta contra a pobreza rural e, mais recentemente, urbana. A partir desse trabalho, criou-se a Associação dos Pequenos Agri-cultores do Estado da Bahia, responsável pela gestão de uma das mais notáveis iniciativas de economia popular da América Latina: a fábrica de tapetes de sisal de Valente, que emprega mais de seiscentas pessoas, tem importância na exportação brasileira do produto e é de propriedade comunitária. É do trabalho da Apaeb também que se originaram as cooperativas de crédito da região. Ver site www.moc.org.br/.

\section{BIBLIOGRAFIA}

ABRAMOVAY, Ricardo. (1981), "Marxistas e cristãos: aqui e agora". Encontros com a Civilização Brasileira, 28 (3, 10), Rio de Janeiro, Civilização Brasileira.

(1998 [1992]), Paradigmas do capitalismo agrário em questão. São Paulo/ Campinas, Hucitec/Anpocs/Edunicamp.

(2004a), "Entre Deus e o diabo: mercados e interação humana nas ciências sociais". Tempo Social - Revista de Sociologia da USP, 16 (2).

(2004b), "A densa vida financeira das famílias pobres", in (org.), Laços financeiros na luta contra a pobre$z a$, São Paulo, Fapesp/Annablume.

ALVES, Carla Freitas. (2004), Agricultura ecológica: do engajamento possivel à retribuição esperada: um estudo dos agricultores ecologistas de Antônio Prado e Ipê - RS. Dissertação de mestrado, Porto Alegre, Universidade Federal do Rio Grande do Sul, Programa de Pós-Graduação em Desenvolvimento Rural.

BECKER, Bertha K. \& LÉNA, Philippe. (2002), "Pequenos empreendimentos alternativos 
na Amazônia". Rio de Janeiro, Universidade Federal do Rio de Janeiro, Rede de Sistemas Produtivos e Inovativos Locais.

BITTENCOURT, Gilson \& ABRAMOVAY, Ricardo. (2001), "Inovações institucionais no financiamento à agricultura familiar". Economia Ensaios, 16 (1): 179-207.

CALLON, Michel. (1998), "The embeddedeness of economic markets in economics", in $\mathrm{M}$. Callon, The laws of markets, Oxford, The Sociological Review/Blackwell Publishers.

CARDOSO, Irene Maria; CARVALHO, Anaôr Fiorini de; BONFIM, Verônica Rocha; SOUZA, Helton Nonato de \& GJORUP, Davi Feital. (2004), "Experimentação participativa com sistemas agroflorestais por agricultores familiares". Anais do $2^{\circ}$ Congresso Brasileiro de Extensão Universitária, Belo Horizonte, Universidade Federal de Viçosa e Centro de Tecnologias Alternativas.

COHN, Gabriel. (2003), Crítica e resignação: Max Weber e a teoria social. São Paulo, Martins Fontes.

COSTA SOBRINHO, P. V. (1992), Capital e trabalho na Amazônia ocidental: contribuição à bistória social e das lutas sindicais no Acre. São Paulo, Cortez.

DUMONT, Louis. (2000), Homo aequalis: gênese e plenitude da ideologia econômica. Bauru, SP, Edusc.

FERRARY, Michel. (1999), "Confiance et accumulation de capital social dans la régulation des activités de crédit". Revue Française de Sociologie, 40, jul.-set.

FLIGSTEIN, Neil. (2001), The architecture of markets: an economic sociology of twenty-firstcentury capitalist societies. New Jersey, Princeton University Press.

FORRESTER, Vivianne. (1996), L'horreur économique. Paris, Fayard.

GARCIA-PARPET, Marie France. (2003), "A construção social de um mercado perfeito: o caso de Fontaines-em-Sologne". Estudos
Sociedade e Agricultura, 20, CPDA.

GRANOVETTER, Mark. (1985), "Economic action and social structure: the problem of embeddedness". American Journal of Sociology, 91 (3): 481-510, nov.

. (2002), "A theoretical agenda for economic sociology", in Mauro Guillen, Randall Collins, Paula England e Marshall Meyer (eds.), The new economic sociology: developments in an emerging field. Nova York, Russell Sage Foundation.

HIRSCHMAN, Albert O. (1986 [1984]), A economia como ciência moral e politica. São Paulo, Brasiliense.

JUNQUEIRA, Rodrigo \& ABRAMOVAY, R. (2005), "A sustentabilidade das finanças solidárias". Revista de Administração da USP, 40 (1): 19-33.

JUNQUEIRA, Rodrigo \& MAGALHÃES, Reginaldo. (2007), Solidariedade social e racionalidade econômica: experiências de um novo cooperativismo de crédito São Paulo, Saint Paul.

MAGALHÃES, Reginaldo Sales. (2003), "A importância das instituições e das redes sociais no desempenho dos mercados financeiros". Trabalho apresentado no XLI Congresso da Sociedade Brasileira de Economia e Sociologia Rural - Sober, Juiz de Fora.

MARECHAL, Jean-Paul. (2000), Humaniser l'économie. Paris, Desclée de Brouwer.

NEE, Victor. (2003), "A new institutional approach to economic sociology". CSES Working Paper Series, Paper 4, Center of the Study of Economy and Society, Cornell University.

NORTH, Douglass. (1990), Institutions, institutional change and economic performance. Cambridge, Cambridge University Press.

NOVAES, Regina Reyes. (1987), De corpo e alma: catolicismo, classes sociais e conflitos no campo. Tese de doutorado, São Paulo, Departamento de Ciências Sociais da 
Faculdade de Filosofia, Letras e Ciências Humanas da Universidade de São Paulo (datilo.).

OLIVEIRA, Ildes Ferreira de. (2002), Economia solidária, desafio do século XXI: a experiência da APAEB - Valente. Feira de Santana, UEFS (datilo.).

PACE, Richard. (1992), "Social conflict and political activism in the Brazilian Amazon: a case study of Gurupa". American Ethnologist, 19 (4): 710-732.

PERRET, Bernard \& ROUSTANG, Guy. (1993), L'économie contre la société: affronter la crise de l'intégration sociale et culturelle. Senil, Cllection Esprit.

PIERUCCI, Antônio Flávio. (2003), O desencantamento do mundo: todos os passos do conceito em Max Weber. São Paulo, Editora 34.

RIBEIRO, Eduardo M.; GALIZONI, Flávia M.; DANIEL, Lilian O. \& RAMOS, Rosana V. (2000), "Agricultura familiar e sustentabilidade no Vale do Rio Jequitinhonha, Minas Gerais: a proposta do Centro de Agricultura Alternativa Vicente Nica. Sober. Disponível no site http://gipaf. cnptia.embrapa.br/itens/publ/sober2000/r ibeiro/Paper0432.

SEN, Amartya. (1982), "Rational fools: a critique of the behavioral foundations of economic theory", in A. Sen, Choice, Welfare and Measurement, Surveys, Ch 4.

WEBER, Max. (2000), Economia e sociedade: fundamentos da sociologia compreensiva. Brasília, Editora Universidade de Brasília.

(2004), A ética protestante e o espírito do capitalismo. São Paulo, Companhia das Letras.

ZELIZER, Viviana. (1997), The social meaning of money. Princeton, Princeton University Press. 


\section{A FORMAÇÃO DE UM MERCADO DE MICROFINANÇAS NO SER- TÃo DA BAHIA}

Reginaldo Sales Magalhães e Ricardo Abramovay

Palavras-chave: Mercados; Microfinanças; Microcrédito; Racionalidade; Sociologia econômica.

Este artigo analisa as bases culturais e organizacionais subjacentes à formação de mercados financeiros formais em regiões de baixa-renda. A ação das Comunidades Eclesiais de Base e dos sindicatos de trabalhadores rurais, a partir dos anos de 1970, foi decisiva para promover um processo de mudança cultural e a formação de uma densa rede de organizações que possibilitaram ampliar o acesso dos agricultores ao mercado financeiro e a novos canais de comercialização. Procuramos reconstruir os processos históricos que levaram à formação das cooperativas, revelando-se como fatores fundamentais a influência do clima sobre os mercados, a racionalidade econômica do sertanejo e as estruturas sociais das novas organizações econômicas.

\section{MICROFINANCE'S MARKET FORMATION IN THE SERTÃO OF BAHIA}

Reginaldo Sales Magalhães e Ricardo Abramovay

Keywords: Markets; Microfinances; Microcredit; Rationality; Economic sociology.

This paper analyses the organizational and cultural basis over which financial markets in poor regions are built. The action of grassroots organizations (as the basis of communities of the Catholic Church) has been especially important in the promotion of a cultural change process and in the formation of a thick network of organizations which enlarged the access of farmers both to financial markets and new channels of commercialization. This paper reconstructs the historical processes of constitution of credit unions, showing especially the influence of natural factors (as the climate, for instance) over the "sertanejo's" rationality and the social structures of the new economic organizations.

\section{LA FORMATION D'UN MARCHÉ DE MICROFINANCES DANS LE SERTÃO DE BAHIA}

Reginaldo Sales Magalhães et Ricardo Abramovay

Mots-clés: Marchés; Microfinances; Microcrédit; Rationalité; Sociologie économique.

Cet article analyse les fondements culturels et organisationnels sousjacents à la formation de marchés financiers formels dans les régions à bas revenu. L'action des Communautés Ecclésiales de Base et des syndicats de travailleurs ruraux à partir des années 1970, a été décisive pour promouvoir un processus de changement culturel et de formation d'un important réseau d'organisations qui ont permis d'élargir l'accès des agriculteurs au marché financier et aux nouvelles issues de commercialisation. Nous tentons de reconstruire les processus historiques qui ont mené à la formation de coopératives et révélés, comme facteurs fondamentaux, l'influence du climat sur les marchés, la rationalité économique du paysan et les structures sociales des nouvelles organisations économiques. 